\title{
Visual Storytelling: Unlearning Gender Stereotyping Inside Classroom
}

\author{
Anita Dhungel
}

\begin{abstract}
This paper introduces 'stereotype', 'prejudice', and 'discrimination', and points out that the three revolve around and remain in a vicious association. Many stereotypical presentations found in educational materials have been explored in the article. the author has stressed the need for developing the qualities of compassion, tolerance, respect for individuals, and preserving their identity through education-so that stereotyping or discriminatory acts can be avoided altogether.
\end{abstract}

Key words: Visual storytelling, gender stereotyping

\section{Introduction}

The terms 'stereotype', 'prejudice', and 'discrimination' are often used interchangeably in every day conversation. The strategy to stereotype is socially constructed by dominant mainstream power holding groups, to subjugate and humiliate the weak groups of people. So, the terms need to be discussed from a sociological perspective, hence it is important to define them here. Stereotypes are oversimplified ideas about groups of people; prejudice refers to thoughts and feelings about those groups, while discrimination refers to actions toward them (Merriam Dictionary). Broadly speaking, stereotypes dominate human social life, where they are transformed into prejudices, and subsequently into acts of discrimination. Stereotypes can be based on race, ethnicity, age, gender, or sexual orientation-almost any characteristic. Stereotypes can be positive (for example when women are mentioned as less likely to complain about physical pain); but most often they are negative (women are stupid and lazy). In fact, people invent stereotypes when they are incapable of acquiring all information needed to make a reasonable judgment about a group of people or an individual belonging to a particular ethnic community.

In either case, stereotype is a generalization that does not take individual differences into account; moreover, new stereotypes rarely get created. Rather, they are recycled and repeated in new ways to describe, subjugate, and humiliate. Essentially, stereotypes spring out from prejudices. Prejudice refers to beliefs, thoughts, feelings, and attitudes that someone holds about a group of people, for instance, crediting and taking the statement that "All Asians are whizz kids" as truth and certainty, creates prejudices. A prejudice is not based on 
experience; instead it is a prejudgment, originating outside of actual experience. Prejudgment then leads to discriminatory acts against individuals, that again lead to stereotyping. All these three conceptsstereotyping, prejudice, and discrimination-revolve around and remain in a vicious association. Conversely, today is the age of gender fluidity, which calls for compassion, tolerance, and respect for each body, form, figure, space, individuality, and identity, besides many other issues and concerns. That is why these values - essentially from preschool or primary level - need to be shared, absorbed, circulated, instructed, and taught through education systems, so that stereotyping or discriminatory acts can be avoided altogether.

\section{Stereotypes in textbooks}

Sadly, many textbooks in Nepali schools teach stereotyped gender images and prejudices that discriminate with examples like, "Boys play outdoor games because they are physically strong", and "Girls are gentle, because they love to play indoor games only." These are some examples unmistakably present in Samajik Sikshya Class Five books, which are taught to the children particularly in government run schools. Out of the many stories included in an English textbook of Class Six, one story focuses on a Brave Female Pilot and the other on George Stephenson - the famous scientist. Both stories are pleasant, one talks about bravery, while the other hones.

One is about a female, while the other is about a male. The male, despite the adversities, yet manages to create something beneficial for mankind. The female, despite being brave, manages to crash the airplane. Though at surface level the stories look innocent, yet an evolving mind will undeniably read that females can never be a competent pilot. This message is already inscribed in the mind by culture, and thus by reading these kinds of stories, stereotyping practice gets amplified. Consequently, this trains young minds to stereotype and always remain prejudiced towards females, career, and bravery.

Another instance on gender stereotyping, which the author has witnessed, is when she heard kindergarten students (in some English medium schools in and around Bhatbhateni/Baluwatar) being taught nursery rhymes that teach little minds the norms of simple differentiation. "What are little boys made of? Snips and snails, / and puppy dog tail's, / That's what little boys are made of" and "What are little girls made of? Sugar and spice, / And everything nice, / that's what little girls are made of". The purpose was very simple. Despite the intention being innocent, yet the consequences were that it prepared minds to stereotype, which could evolve into prejudices, thenceforth discriminatory acts later in life. What one must remember is that, whether it be the nursery rhymes, the word images, stories, case illustrations and activities taught inside a classroom to a budding mind, will be well remembered for an extended period of time.

This in turn will frame and shape sensitivity and thoughtfulness, which may or may not evolve to be heedful or sensitive towards gender differences. That is why gender sensitivity lessons must be given to a child from a very early age. Perhaps the best practices which can be used to instruct young children - so as to effectuate best results possible - would be via visual storytelling. For instance, bring in images of neutrality, or an image that goes against the grain, like a boy crying or playing with dolls and a girl playing football and the other image could be of a girl putting the ball inside the goal pit. This could generate an interactive environment. However, a 
compelling story with a coherent narrative structure on gender sensitiveness requires a lot of attention to detail. Therefore, a teacher or an instructor must plan lessons well ahead of class time. Spending a little extra time on storytelling during lesson slating will keep the learning experience highly engaging, creative, and truly dynamic.

To begin, teaching instructors could take up common clichéd categorizations as examples to sensitize, train, and prepare young minds away from stereotyping and prejudices. For instance: "All blonde women are stupid," "All red heads are fiery," "All Indian women are wild, glamorous, and exotic," "All Indians are deeply spiritual," "Girls are only concerned about their physical looks," "Women who smoke and drink do not have any decent values," "All Asians are math wizards," "All Latinos are good dancers," etc. Teachers could ask students to identify whether the statements are true or false, and then instruct each student to discuss and write the why or why not's.

Begley (2000) thinks discussing clichéd stereotypes will open up minds and broaden horizons not to make erroneous prejudices, hence discriminate. And these kinds of prejudgment can be found in the arts, myths, fairytales, poetry, fiction, biographies/autobiographies, etc., which actually shape a mind from a very early age. For instance, in Hansel and Gretel story, Hansel is shown as a boy with strong sense of leadership, whereas sister Gretel is dependent on brother Hansel to find the trail back home (Grimm \& Grimm, 1812).

These kinds of stories create negative images of persons or individuals in a young and budding mind of child. Sharon Begley believes that stereotypes from 'white men can't jump' to 'girls can't do math,' are "negative images that are pervasive in the culture (which) can make us choke during tests of ability. . . The power of stereotypes, scientists had long figured, lay in their ability to change the behavior of the person holding the stereotype. ." (Begley, 2000, pp. 66). Stereotyping transpires in a similar vein, when what is written in literature conditions a mind to believing it as containing truth value.

For instance, in Austen's Pride and Prejudice (1813), Darcy is talking to Miss Bingley about a lady's behavior and comments: "A lady's imagination is very rapid; it jumps from admiration to love, from love to matrimony in a moment" (p. 88). These words put ideas into a person's mind that a woman's only preoccupation when meeting the opposite sex - that is male - is to get married to him. This is a prejudice which people have believed since ages and is practiced as containing commonsense truth value, even today, in certain societies or ethnic communities.

In the contemporary world, however, when women are so career-oriented and strive towards professionalism in any form/ discipline or profession, this kind of definition no longer hold water. Yet, if these categories of ideas are held when hiring a woman for a particular job-as containing truth value -, then it is discrimination. Discrimination also consists of actions against a group of people. Discrimination can be based on different kinds of gender, age, religion, and health. So, when these kinds of definitions are circulated, discriminatory action against women is going to occur, and prejudices and stereotypes are going to be constructed repeatedly. Accordingly, gender stereotypes need to be dealt with strongly from early education. 


\section{Gender stereotyping: A common experience}

As exaggerated images of men/women or boys/girls are deployed repeatedly in routine life, it most obviously becomes an inherited habit-a legacy that each individual inherits. Surely, stereotyping arises outside of conscious awareness and as a part of "natural" social and cultural interface, which must be truly discarded. This is possible if gender conscientious education is initiated, which could eventually create level-headed individuals. In fact, stereotyping is not only hurtful, it is also wrong. Besides, it can also

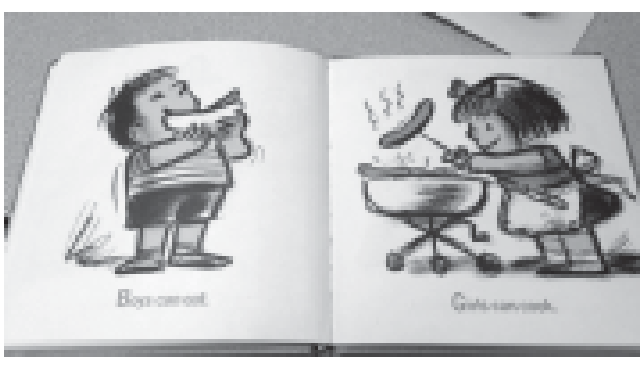

Figure $\mathbf{1}^{1}$ Boys are active and dominant, whereas girls are submissive and domestic

lead to bullying from a very young age, for an innocent mind may carry this "twisted" legacy into adulthood, which has the potential of turning into violence. This readily stereotyping behavior then can be warped around and used against a woman to exploit, subjugate and dominate her. Indeed, acceptance of images as customary and commonsensical confers their endorsement. By practicing them repetitively, however, stereotypes get normalized in life. Actually, by looking at these images, we get meanings and descriptions like: Girls are emotional, flirtatious, accepting; they like to cook, clean, sew, and stay at home, concentrate on make-up, but excel in verbal skills, whereas boys are aggressive, dominant, brusque, confident, like to play outdoors, and excel in math skills.

A stereotyped image-of a man or a woman's performance, behavior, attitude, and aptitude -in today's world, is generally communicated via the visual mass media.

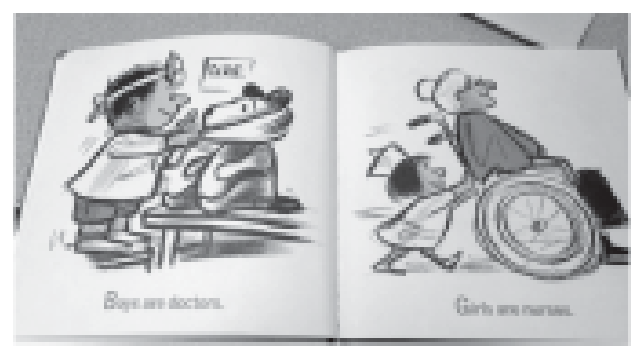

Figure 22: Boys are encouraged to take careers where the demand is to be brave and daring, whereas girls are propagandized to take submissive and passive career roles

The images - of both men and women in various activities - travel the cosmos and come to us through our TVs into our family room. Essentially, we are watching, perceiving, and consuming these similes obliviously, thousands and thousands of miles away, via virtual reality. We are then effectively manipulated by the portrayals; consequently, we begin to manage our life by performing or acting out in a similar manner, for instance, "Boys do not cry" and "Girls cry a lot"; "women love to shop; men hate shopping"; "parenting comes more naturally to women than it does to men." The stereotypes are customarily fabricated to suggest "boys need to be tough," whereas "girls are emotionally unstable." Labeling occurs through unusual cases of fantasy, which is an overt form of

${ }^{1}$ https://mrlibrarydude.wordpress.com/tag/picture-book/

${ }^{2}$ https://mrlibrarydude.wordpress.com/tag/picture-book/ 


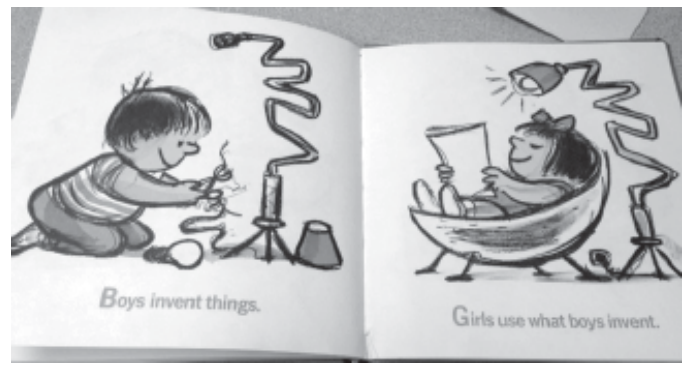

Figure 3: Boys are imaginative and creative whereas girls are docile and unimaginative

language game playing, and is actually one of the significant aspects in the pillar of socialization. For instance, in the poem "Girl," by Jamaica Kincaid - an Antiguan American Poet - the instructions below are advice given by an adult, probably the "Girl's" mother.

\section{Jamaica Kincaid's "GIRL"}

this is how you smile to someone you don't like too much; this is how you smile at someone you don't like at all; this is how you smile to someone you like completely; this is how you set a table for tea; this is how you set a table for dinner; this is how you set a table for dinner with an important guest; this is how you set a table for lunch; this is how you set a table for breakfast; - - - - - - - - ----------- this is how to make a bread pudding; this is how to make doukona; this is how to make pepper pot; this is how to make a good medicine for a cold; this is how to make a good medicine to throw away a child before it even becomes a child; (Kincaid,1983)

We get illustrations of labeling in this poem. This abets stereotyping the girl's images and we accept all the form of work she is

${ }^{3}$ Brannon, 2000. advised to perform as common sense. And we believe that it is the proper and fitting way for a girl to perform as advised in the poem. In the poem, one observes gender stereotyping as "given," ideologically and materially. Consequently, society, too, organizes its structures and measureable services to accommodate these understandings.

The ideology in the poem is sure to generate some kind of hate, within the "Girl," which could move in any direction: The first step maybe towards fear and the second step she could take would be towards violence or with the suppression of her feelings and desires via instructions, thus she could be a violent person. Basically, she is imprisoned with words, which may lead to a total rejection of her situation and mutiny can yield various forms. To clarify, let me cite an example how stereotyping is closer to home and that which joins us all: the celebration of Mother's Day (Matha Tirtha Aausi) and Father's Day (Kushe Aausi) in Nepali society and culture. When we offer gifts to Aama it is typically a sari, or a dhoti, or kurthasulwar, which is pretty and colorful, or maybe something concerning makeup - all the girly and womanly stuff; whereas for Buwa it is usually a tie, a shirt, which has a dull and somber color, or a musk smelling After Shave perfume, which we regard as "boyish or manly" stuff.

This act of unconsciously choosing gifts is just one of the countless ways in which we perpetuate stereotypes and biases, on what men and women are supposed to be like and to like. Essentially, these biases filter down to us through media, marketing, language, society, culture, and educational institutes; these images condition us to assume deductions as true. Moreover, we then expect that this is the way we must act upon. The moment one does not follow norm, the individual then is quickly ostracized by society. Thus, the learnt 
gender roles structure the various "parts of actions" which individuals perform throughout their lives. These actions impact aspects of daily life from choice of clothing to occupation, which we begin learning from a very early age. Candace West and Don H. Zimmerman in "Doing Gender," likewise state that the conditioning of a baby's mind and thought processes activates itself in the delivery room - in infancy-from the moment of birth. Socialization of her/his body begins therespecifically, when the child's parents or the nurses at the hospital dress little boys in blue and little girls in pink, to distinguish which sex the body of the baby belongs to.

The sooner the differentiation, the clearer will be the marks of society on the body (West \& Zimmerman, 1987, pp. 129-131). The color functions like an index-a standardized rod-which people use to correlate, connect and interact with the baby. Social pacts locate the scripts and limit not only the bodies, but also those people surrounding them to interact with them in accordance with conventional norms created as suitable for a particular form of body. This highlights Simone de Beauvoir's dictum and can be applicable to both genders: "One is not born, but rather becomes a woman or a man." This dictum also establishes Judith Butler's argument that sex and gender are not ontological originations, but are rather social constructs (584). J.E.O. Blakemore et al., (2009) state, ". ... that which we think as "womanly" or "manly" behavior is not dictated by biology, but rather is socially constructed. And a fundamental domain in which gender gets constructed is language use... Language does not merely reflect a preexisting sexist world; instead, it actively constructs gender asymmetries within specific socio-historical contexts" (119120).
Brannon (2000) classifies how the cult of femininity or masculinity - and putting them in stereotyped typecasts- began with the invent of religiosity and its conviction by patriarchal structures. Thenceforth, through unconscious consensus and repetitive use of language descriptions, mankind trained themselves to label, classify, and place them within certain categories.

\section{Table 1: Cult of femininity and masculinity}

\begin{tabular}{|l|l|}
\hline $\begin{array}{l}\text { The cult of true } \\
\text { womanhood }\end{array}$ & $\begin{array}{l}\text { Male sex role } \\
\text { identity }\end{array}$ \\
\hline $\begin{array}{l}\text { Piety: True women } \\
\text { are naturally } \\
\text { Religious }\end{array}$ & $\begin{array}{l}\text { No sissy stuff: A } \\
\text { stigma is attached } \\
\text { to feminine } \\
\text { characteristics }\end{array}$ \\
\hline $\begin{array}{l}\text { Purity: True } \\
\text { Woman are } \\
\text { sexually } \\
\text { uninterested }\end{array}$ & $\begin{array}{l}\text { The big wheel: Men } \\
\text { need success and } \\
\text { status }\end{array}$ \\
\hline $\begin{array}{l}\text { Submissiveness: } \\
\text { True women are } \\
\text { weak, dependent } \\
\text { and timid }\end{array}$ & $\begin{array}{l}\text { The sturdy oak: Men } \\
\text { should have } \\
\text { toughness, } \\
\text { confidence, and } \\
\text { self-reliance. }\end{array}$ \\
\hline $\begin{array}{l}\text { Domesticity: True } \\
\text { women's domain } \\
\text { is in the home. }\end{array}$ & $\begin{array}{l}\text { Give "Em Hell: Men } \\
\text { should have an } \\
\text { aura of aggression, } \\
\text { daring, and } \\
\text { violence. }\end{array}$ \\
\hline
\end{tabular}

(Brannon, 2000)

Brannon's (2000) diagram (below) suggests that we complete the action of stereotyping via physical appearance, traits, behaviors, and occupations. For example, we say and teach children with sentences such as: Boys are more resilient than girls; boys are fit to be doctors, and as girls are soft and emotional, they are fit to be nurses. We 
teach these lessons through repetitive illustrations, whereby they acknowledge and confirm to them by acting out in a similar manner, believing it to contain truth-value, for it is apparent/teacher (commanding and authorial) who has taught them. Thus, the word game of stereotyping is repeatedly played out and subconsciously absorbed into our blood system, which in turn becomes a habit. In fact, an infant is exposed to these lessons from a very early age. $S /$ he begins reading stories as a toddler through various images, where there is gender stratification. This

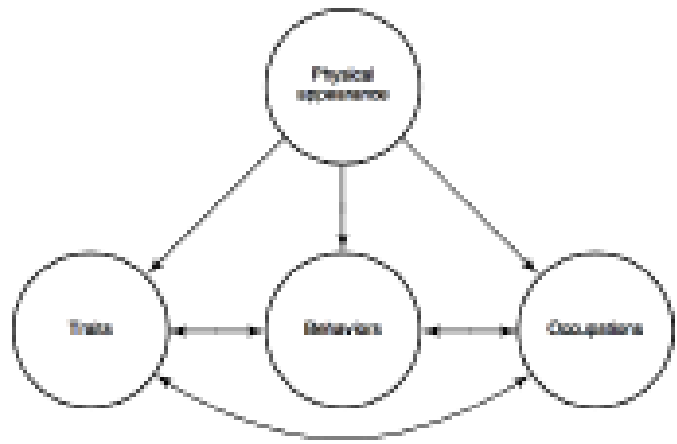

Figure $4^{1}$

ultimately leads to imprison, establish, and confirm personae within certain stereotype parameters. Actually, research has shown that by around age 3, for example, most children can accurately identify another child's sex and about half of them can correctly label toys by gender (Blumberg, 2008 , p. 12). The next stage of learning to label and classify happens via language use when the infant grows and attends school.

Language/words allow/s children to differentiate and label genders based on expectations of society and culture in which they have been located in to learn. For instance, they base their decisions on the likes and dislikes of certain ideas which they may have picked up in a domestic environment or in a classroom situation, through instructional materials. S/ he is then taught norms, which convey the false message that the norm presented through these images and descriptions, is the natural, the real truth. Through these lessons, boys and girls are assigned the norms, roles, expectations and social spaces for male and female identity. Research has shown that by age 5 most children can do all of it flawlessly (Ruble \& Martin, 1998) and children's toy preferences reflect these beliefs. Also, research has shown that girls are more likely to list dolls, stuffed animals and educational activities as their favorite toys, whereas boys are more likely to list manipulative toys, vehicles, and action figures as their favorites. Cherney and London (2006) in their research of young kids found that boys' preference for masculine television programs and girls' preference for feminine television programs increased with age.

Moreover, Levy, Sadovsky, and Troseth (2000) in their research entitled "Aspects of young children's perceptions of gendertyped occupations," also found that gender-associated beliefs could affect the roles children expect to fulfill when they imagine to become adults. For example, they found children's predictions about their happiness in future occupations reflected gender stereotypic beliefs; more boys expected to be happy in a masculine occupation and more girls expected to be happy in a feminine occupation and these were intensified by school lessons. Children develop dexterity and flexibility in pigeonholing as they approach adolescence, which confers them more room to play around with variations of stereotyping, prejudices, biases, and discriminations.

Horton $\left(23^{\text {rd }} \mathrm{Feb} 2016\right)$ narrates his story like this: "In the office where I worked at the 
time my son was a baby, we had a dry-erase board to show where people were when out of the office. When female coworkers were out with their children, someone would write on the board "sick daughter" or something similar. When my son was sick, I would return to find a notice proclaiming I was out "babysitting." . . . I was trying to raise awareness of the importance of fathering, but I generally only succeeded in raising a chuckle ....I also noticed that when I went to a doctor's visit with his mother, the doctor and nurses would speak to her even when I was closest or even when I was actually holding my son. It was clear that the mother was the default parent and the father, no matter how involved, could only provide auxiliary services. I . . quit my job and stay home full time. . . . Many people would congratulate me on being in touch with my "feminine" side. Others would offer an indirect criticism with a loaded question such as, "How does your wife feel about you staying home full time?"

Any mention of something gone wrong with the baby that day, I was generally met with, "Well, now you know what women have faced for centuries! Women (and nurturing men) have suffered from bias and disrespect for centuries ..." And imagine we live in the $21^{\text {st }}$ century. This story shows essentially how the tendency to make exceptions at stereotyping increases as the child grows and matures into adulthood. Because of this unseen omnipresent power of stereotyping boys/girls also come up with statements like insects always frighten girls or only boys are rough while playing; Or only fair and slim girls are pretty, whereas only dark boys with V-shaped bodies are handsome; Only girls can take care of babies, boys cannot; boys can repair cars and women can repair clothing, respectively. The children cannot escape the trap they have been located within, for without realizing they practice what they have been taught to take as truth-value. Moreover, these images carry a truth-value for them, for it is in a textbook, recommended and prescribed to them as part of class syllabi/ curricula, which they are supposed to read to gain knowledge.

Nepali schoolrooms and textbooks are not different. Primarily, books on English stories or Social Sciences are full of these kinds of stereotyping images: Women shopping; men taking control of accounts; girls shown cooking food or cleaning the house, or tending as a nurse to the sick and the elderly; whereas men as Presidents and in influential positions, a Gurkha soldier fighting in the armed services with a gun (never a woman with a gun), etc. Images and stories of these stereotyped lifestyles are represented unknowingly as part of the reading material. Basically, as children attend school, they are given instructions through textbooks - where boys/males, girls/females are typified in various social/ cultural roles. Hence children become indoctrinated, brain-washed, trained and prepared to take on life via this process of socialization, plus the entire gamut of cultural responsibilities.

Shrestha (2016) comments: “More than 80 per cent of Nepali students go to government schools first, but Kathmandu's neglect of public education is reflected in the mainstream media's lack of interest in government schools and teachers." Shrestha discusses this issue with Rajendra Dahal of Shikshak Magazine who adds, "The choice for a large number of students is government schools but public education has always remained in the shadows." Rajendra Dahal had also examined the poor quality of Nepali textbooks and remarks: "The worst are the books for social studies in both English and Nepali. They show very poor understanding of Nepal's geography, development and history." However, the itemized, hence qualified gendered

$18 \quad$ Journal of NELTA, Vol 21 No. 1-2, $\quad$ December 2016 
stereotypes, coached and implanted into our psyche from a very tiny age across centuries through our own 'conformist educational systems' has resulted much of the prejudices and biases, thereafter effectuating violent intolerances in our conduct and outlook. We need to alter this outlook and take action immediately.

So, maybe as teachers we could help change the outlook of children by showing them images which are gender unbiased and impartial (Calvanese, 2007). Sharma (2015) writes:

Textbooks published by private companies are no better. Health Population $\mathcal{E}$ Environment Education for Today (republished by Ratna Pustak Bhandar) defines virility as the "feeling of proudness on having children" and declares [that] "sterile people are hated by society." Warming up to the subject, the all-male writers of this textbook propose "educating women to get employed" as one measure to prevent HIV/AIDS. (7-13 August 2015)

Twenty-first century is a witness to a constellation of intellectual trends and rapid shifts in ideas, concepts, and its practices. Yet, we are still practicing the same old norms of stereotyping. The concurrent century certifies to the utilization of novel and state-of-the-art interactive pedagogic strategies, outside and inside a classroom. Yet, vast difference is clearly visible between statements (promises) and the implementation of these strategies inside a Nepali classroom specifically.

In fact, Sharma (2015) in his article provides examples of the erroneous labeling that he found in Nepali textbooks. He illustrates how stereotyped messages and examples that are taught inside a classroom.
The example he provides is that of a class eight textbook.

A couple's desire is to be a guardian of their child or children. This is their parental property. In the context of our society the in-fecund or sterile couples or one of them are hated by their neighbors, relatives and others. In this way there is a concept in a society that marriage is for bearing child. Parents having child after the short duration of marriage think of being fortunate in our society.

\section{Virility}

The feeling of proudness on having children is called virility. Many people show their society being successful in life by giving birth to a child. Sterile people are hated by society. Such couples are always dominated by the couples or persons who have child or children.

\section{Flourishing family's prestige}

Family void of son is trivial. The concept of male birth in a family is an orthodox view of traditional people. They are running after such belief; so do not accept the existence of that family which lacks son. Due to son preference, many couples wait for son though they already have a half dozen daughters. . ..( Sharma, 2015)

Similarly, he says how in a Grade 7 Nepali language Social Studies textbook declares 'journalism is propaganda'; and then how in a recent Accounting textbook he found descriptions which read like this: "Secretaries should be good-looking and wear lipstick." He further gives examples of "other textbooks for Grade 9, children are seen asking their father for permission to watch TV and their mother for permission to eat bread." And then "One 
question asks students to look at different pictures of Nepalese and guess their ethnicity. In an English textbook published by the government, a character named Kaji Sherpa climbs mountains. The book defines a Sherpa as 'a person who takes long walk in the hills and the mountainside (Sharma, 2015). The offered evidences depict that many Nepali textbooks do have descriptions which stereotype. These descriptions have not been identified as yet, for it is very difficult to distinguish, for many of the descriptions found in them have hegemonic influence. Most of the stereotypes are taken as common sense, hence not much action has been taken to neutralize them.

So, maybe an instructor could begin with different kinds of story; for instance, personal tales from a student's or a teacher's experience which could create bonding, while stories could stimulate imagination and move away from stereotyping. Humans are storytelling creatures for ages and we have been delving inside our core imagination to tell stories. Why not pick up those same stories familiar to us, for instance, Laxmi Prasad Devkota's poem Latoko Trisana (1967) - and via its narratives try to identify diction/ labels that stereotype. While stories do have a profound effect on us due to its emotional content, it is commonly known how once you pick up a story that interests you, it does not allow you to move away from it without reading it completely. Thus, identifying stereotypes within the narratives and examining, reviewing, and discussing it out in the open, I believe, would support in combating stereotyping, and would also facilitate to develop a gender-neutral and gender discerning world.

Maybe, by taking the same story of the female pilot in the English book of grade six, one could discuss that females are equally competent, and it was because of her quick thinking, the airplane could be saved. Giving examples with positive and encouraging messages could also be one of the ways to neutralize stereotyping gradually. Another way could be by engaging students in a number of songs, which are popular in our daily lives - for instance Narayan Gopal's song, "Mero Uthne Palo" or Tara Devi's Song, "Uukali Oraliharuma" or even Kumar Basnet's song, "Aamabhanda Chhori Taruni," and through the songs teach/train students to identify stereotypes and then prepare them to undo the harm; or come up with activity as given in the table below and stimulate students to come up with the responses that do not discriminate nor stereotype.

\section{Activity}

- Get two identical dolls, dress one in blue and the other in pink. Write down 12 mixed up gender stereotypical feminine and masculine words. Then get the students to assign 6 'words' to one of the dolls.

- The teacher will note that the student will assign words based solely on the color of the dolls clothes. Then the teacher can facilitate the class by talking about gender being assigned at birth, in the hospital room. Try to work them up to find the reasons why it has happened and whether color makes any difference to an individual's personality?

- An alternative method is to use pictures of male and female toys together with either a picture of a baby in pink or blue.

- Another activity involves gathering up a bunch of fashion magazines and randomly passing them out to class. Ask them what they think of the male and female models presented in these magazines (gender roles, body image, personality, career, etc.) (Cherney \& London, 2006) 


\section{Conclusion}

To conclude, I would like to end with a series of thought provoking questions and some suggestions. Do you suppose your classroom teaching of gender stratification supported by the visual media images is doing disservice to all-men, women, and children? Do you believe that these sexualized, stereotyped but mythical impressions of masculinity and femininity are distorting our sense of truth and balance? Do you believe that we must do away with sexualized or stereotyped images? How do you suggest we move ahead and deal with these hegemonic power-vested images, which circulate freely, in our society?

\section{Questions for consideration}

- In spite of the changes in our society, how seriously has the male breadwinner notion been dislodged?

- What are the traditional notions of a career path for Nepali womanhood as thought to be most appropriate?

- Would males in our society accept women as the bread winner of the family?

- How do we get to the point where we accept men as being strong?

- Would men in Nepal Army want to hold jobs alongside women - as women in combat?

- How do we get to the point where we accept that in spite of women bearing children and being perceived to be vulnerable, they are still equal strong partners of men? (Cherney \& London, 2006)

Probably we could engage students in an interactive manner inside a classroom with some interesting and some constructive decision making lessons, which would help them to throw away the blanket from their eyes. For instance: impartial story reading, role playing/acting with readings as well as with activities and questionnaires, etc. would help them to identify and wade out of the confusions that these stereotypes create in their minds. Conceivably again, then this gender tolerant and neutral world would look at humanity solely through the lens of creativity, capability, and competence.

\section{References}

Austen, J. (1813). Pride and prejudice. NY: Barnes \& Noble Classics.

Beauvoir, S. D. (2011). The second sex. NY: Vintage eBooks.

Begley, S. (November 6, 2000). The stereotype trap. Newsweek, pp. 66-68.

Blakemore, J. E.O., Berenbaum, S.A., \& Liben, L.S. (2009). Gender development. NY: Taylor and Francis.

Blumberg, R.L. (2007). Gender bias in textbooks: A hidden obstacle on the road to gender equality in education. Paper commissioned for the EFA Global Monitoring Report 2008, Education for All by 2015. United Nations Educational, Scientific and Cultural Organization.

Brannon. (Nov 6, 2000). Gender stereotypes: Masculinity and femininity: The stereotype trap". Headline. Newsweek. www.ablongman.com/partners_in_ psych /PDFs/.../Brannon_ch07. pdf. Accessed: 26 $6^{\text {th }}$ Jan 2016.

Butler, J. (1990). Gender trouble: Feminism and the subversion of identity. NY: Routledge.

Calvanese, M. M. (2007). Investigating gender stereotypes in elementary 
education. Teacher gender and competency. Connecticut State University: Journal of Undergraduate Psychological Research, 2, 1-8.

Campbell, A., Shirley, L., \& Candy, J. (2004). A longitudinal study of gender-related cognition and behavior. Developmental Science, 7, 1-9.

Cherney, I.D. \& London, K. (2006). Genderlinked differences in the toys, television shows, computer games, and outdoor activities of 5- to 13-year-old children. Sex Roles, 54, 717-726.

Devkota, L.P. (1967). “Latoko trisana: PaniHaso. Manoranjan: Kavita Sangraha. Kathmandu: Nepal Sanskriti Sangha. p. $40-42$.

Grimm, J. \& Grimm, W. (1812). Hansel and Gretel. Short Story America. www.shortstoryamerica.com/pdf_ classics/grimm_ hanse_and_ gretel.pdf. Accessed: January 2016.

Horton, R. (Feb, 2016). Still not a babysitter: At-home dads, then and now. US: The Huffington Post. www.huffingtonpost. com/randall-horton/still-not-ababysitter-at-home-d... Accessed: 23 Feb 2016.

Kinkaid, J. “Girl.” (1983). https://d2ct263 enury6r.cloudfront.net/mAyAZX 5yjR1CTUVTqlvLuDtnyDIATIYLqshu MeIxmRxmz1AQ.pdf. Accessed: $26^{\text {th }}$ Jan, 2016.

Levy, G.D., Sadovsky, A.L., \& Troseth, G.L. (2000). Aspects of young children's perceptions of gender-typed occupations. Sex Roles, 42. 993 -1006.

Matlin, M.W. (2012). The psychology of women ( $7^{\text {th }}$ ed.). Belmont, CA: Wadsworth.

Merriam Dictionary. https:// www.merriamwebster.com / dictionary/stereotype. Accessed: $26^{\text {th }}$ Jan 2016.

Ruble, D.N., \& Martin, C.L. (1998). Gender development. In W. Damon \& N. Eisenberg(Eds.). Handbook of child psychology volume three: Social, emotional, and personality development (pp. 933-1016). New York: Wiley.

- - . (2004). Children's search for gender cues: Cognitive perspectives on gender development. American Psychologist, 13(2), 67-70.

Schmitz, A. (2012). Gender Inequality. A Primer on Social Problems. Creative Commonsby-nc-sa 3.0 license. 2012 Book Archive. 2012 books.lardbucket. org/books/a-primer.../s07-genderinequality.html. Accessed: January 2016.

Sharma, S.M. (August 2015). "Laughing it off." Nepali Times. \#770. 7-13, p.10-11.

Shrestha, S. (July 2016). "Teaching Teachers". Nepali Times Buzz. \# 815, P.7.

West, C. \& Zimmerman, D.H. (June 1987). Doing gender. Gender and Society. 1 (2), 125-151.

The author: Associate Professor Anita Dhungel (Ph.D.) is in teaching profession for past 20 years. At the moment, she is M.A. Coordinator for English Literature at Padma Kanya Campus, TU. She is the author of numerous critical literary articles and a couple of short stories. At present her book, Silence in Poetry: A Trope is in press. 